\title{
El impacto de la Revolución Rusa en Uruguay $(1917-1923)^{1}$
}

Gerardo Caetano ${ }^{2}$

Resumen: Las consecuencias de los grandes procesos y acontecimientos de la historia universal (como es el caso de la Revolución Rusa) y su recepción específica por parte de los países de América Latina no ha sido un tema especialmente considerado por nuestras historiografías nacionales. El presente artículo procurará analizar su impacto en el universo político cultural uruguayo, comunistas, socialistas y anarquistas, pero también en los actores dominantes en el escenario político: el batllismo y los conservadores.

Palabras clave: Revolución Rusa - Uruguay - izquierdas - sindicatos - conservadores

\begin{abstract}
The consequences of the great processes and events of universal history (as in the case of the Russian Revolution) and their specific reception by the countries of Latin America have not been a subject especially considered by our national historiographies. The present article will analyze its impact in the Uruguayan political, communist, socialist and anarchist political universe, but also in the dominant actors in the political scene: Batllismo and conservatives.
\end{abstract}

Keywords: Russian Revolution - Uruguay - Left-wing sectors - Workers Union - Conservatives

\section{Introducción}

Las consecuencias de los grandes procesos y acontecimientos de la historia universal y su recepción específica por parte de los países de América Latina no ha sido un tema especialmente considerado por nuestras historiografías nacionales. Acostumbradas a desarrollos nacionales, cuando no provincianos, estas han tomado con frecuencia estos temas con cierta ajenidad, a lo sumo como referencias laterales o conexas que solo sirven para reforzar la noción de la primacía casi absoluta de los procesos locales. La relativa ausencia también -pese a honrosas excep-

\footnotetext{
${ }^{1}$ Trabajo recibido el 11/03/2017. Aceptado el 13/05/2017.

${ }^{2}$ Historiador y politólogo. Profesor Titular de la Universidad de la República, Uruguay. Investigador de NIVEL III del Sistema Nacional de Investigadores del Uruguay. Presidente del Consejo Superior de FLACSO. Contacto: gcaetano50@gmail.com
} 
ciones- de historias propiamente regionales o continentales ha incrementado este débito.

¿Cómo estudiar entonces el impacto en nuestros países de hace un siglo de un proceso complejo y decisivo como el de la «Revolución Rusa»? ¿Cómo hacerlo de manera efectivamente contextual, sin que se caiga en una exacerbación casi determinista de las «influencias» recibidas o en una lectura localista que todo lo hace depender de las variables nacionales? ¿Cómo integrar al conjunto de las fuerzas políticas y sociales en ese contexto de recepción de un proceso de repercusión mundial, evitando la lectura fragmentaria de lo que sucedió en aquellos ámbitos más permeables a esas influencias? ¿Cómo ofrecer, en suma, una lectura más abarcativa y balanceada de un proceso de esta naturaleza, con todas sus implicaciones de diversa índole?

Estas y otras preguntas, con sus consiguientes implicaciones teóricas y metodológicas, son las que se procurará contestar en forma necesariamente sucinta en el artículo presentado. Para ello se seguirá la siguiente «hoja de ruta»: i) se partirá con una visión de conjunto sobre los principales factores que hacían al contexto uruguayo de la época, a partir de lo cual se propondrán las principales hipótesis a desarrollar en el texto; ii) en segundo término, se analizarán las consecuencias de la revolución en aquellos sectores por definición más proclives a una recepción fuerte de estos acontecimientos, con especial hincapié en actores como los socialistas, los emergentes comunistas y los anarquistas, así como su proyección natural en el campo del movimiento sindical; iii) luego se analizará el fenómeno desde el punto de vista de sus repercusiones en la interna y en el accionar público del principal actor nacional del Uruguay de las tres primeras décadas del siglo XX, el gobernante P. Colorado en general y su fracción hegemónica en particular, el «primer batllismo», desde sus posturas de un reformismo radical; iv) finalmente, se analizará la reacción frente a los ecos de la revolución de los actores más conservadores de aquella sociedad enfrentada a un contexto de amplias reformas en diversos planos; v) el artículo culminará con un breve análisis de perfil conclusivo, en el que se retomarán las hipótesis iniciales.

\section{Contexto y principales hipótesis}

Entre 1917 y los primeros años 20 el Uruguay se encontraba en un contexto de cambios profundos, con una fuerte confrontación política 
que enfrentaba en clave polar a dos grandes «familias ideológicas» (el «republicanismo solidarista» liderado por el batllismo y sus fracciones más radicales, frente al «liberal conservadorismo» bajo la conducción del «ala derecha» del P. Nacional). ${ }^{3}$ Las izquierdas socialista y anarquista (con caudales de adhesión marginales $)^{4}$ se encontraban dentro de un perfilamiento general -aunque debatido- de una relativa «izquierdización», empujados en más de un sentido por el radicalismo reformista del batllismo, que configuraba a la vez un competidor efectivo por un electorado de frontera al tiempo que un acicate para una diferenciación clara. Esto también repercutía en el movimiento sindical, en el que predominaban aun los anarquistas, que habían profundizado su hegemonía a partir de la fundación de la Federación Obrera Regional Uruguaya (FORU) en 1905. Desde $1913^{5}$ imperaba un contexto de crisis económica que, a la vez que incrementaba el clima de polarización social y política general (derivado principalmente por el debate acerca del intento de «freno» conservador a las reformas batllistas), aumentaba la conflictividad en el campo laboral y reforzaba las tendencias más «izquierdistas» dentro del P. Socialista y en los círculos anarquistas. ${ }^{6}$

Como principal intérprete de los nuevos tiempos (esos «tiempos de formación» como los llamó el propio Batlle y Ordóñez), el batllismo -como han analizado Barrán y Nahum- nació en la «cuna de oro» del Estado. ${ }^{7}$ Emergió también dentro de la matriz de la vieja tradición colorada, cuyas piezas claves eran el ejercicio mismo del gobierno (que detentaba desde hacía cuatro décadas) y la identificación con el Estado.

El itinerario de aquel primer batllismo es reconocible en una serie de reformas desarrolladas en varios escenarios de la vida del país. Su

${ }^{3}$ Caetano, (2011): 9-16.

${ }^{4}$ En su primera comparecencia electoral en 1910, en coalición con el P. Liberal, con listas solo en la capital, los socialistas obtuvieron 894 votos; en el plebiscito de elección de constituyentes de 1916, en solitario y con listas en varios departamentos, los socialistas obtuvieron 2001 votos, un 1,36\% del total de votantes; en 1917 bajaron a 723, un 0 , $55 \%$ del total; en 1919, con las nuevas reglas electorales garantistas de la Constitución que entraba en vigor, los socialistas (todavía unidos en un mismo partido) ascendían a 4394 votos (2,27\% del total); en 1922, ya divididos, el P. Socialista obtuvo $997(0,40)$ y el P. Comunista $3179(1,29)$. Los anarquistas no participaban de las elecciones pero su peso se daba solo dentro del reducido elenco dirigente del movimiento sindical. Cfr. Caetano, 1992; Nahum, (2007).

${ }^{5}$ Barrán-Nahum, (1985).

${ }^{6}$ López D’Alesandro, (1992).

${ }^{7}$ Barrán-Nahum, (1979). 
plan de transformaciones, que bregaba antes que nada por la integración moderna del país, discurrió por seis grandes andariveles: la reforma económica (nacionalizaciones, estatizaciones, promoción de la industria vía proteccionismo); la reforma social (apoyo crítico al movimiento obrero, otorgamiento de una legislación social protectora y obrerista, desarrollo de medidas de índole solidarista con los sectores más empobrecidos); la reforma rural (eliminación progresiva del latifundio ganadero, promoción alternativa de un país de pequeños propietarios, con mayor equilibrio productivo entre ganadería y agricultura); la reforma fiscal (mayor incremento de los impuestos a los ricos y descenso de los impuestos al consumo, con objetivos también en el plano de la recaudación fiscal y del dirigismo económico y social); la reforma moral (incremento de la educación, defensa de una identidad nacional cosmopolita, anticlericalismo radical, propuestas de emancipación para la mujer); la reforma política (amplia politización de la sociedad, colegialización del Poder Ejecutivo, implantación de institutos de democracia directa).

Todas estas reformas (muchas de las cuales no llegaron a concretarse en su totalidad) no sólo congregaron voluntades entusiastas; también provocaron miedos y resistencias. La primera crisis del batllismo temprano encontró su expresión más rotunda en la derrota electoral del 30 de julio de 1916. En un marco de creciente polarización social y política, ese año fueron convocados los comicios para elegir los integrantes de una Asamblea Constituyente, cuyo cometido sería la reforma de la primera Constitución de 1830. La instancia electoral operó como un verdadero plebiscito en torno al modelo reformista, identificado en esa ocasión con una propuesta colegialista apoyada por el batllismo e indirectamente también por el socialismo. Su resultado fue para muchos sorprendente: la primera vez que se aplicaba el voto secreto y el sufragio universal masculino, la ciudadanía uruguaya se pronunciaba categóricamente en contra del gobierno y de su propuesta reformista.

El año de 1916 delimitó así la paradoja constitutiva de la moderna democracia uruguaya. A simple vista, el freno al reformismo en las políticas públicas -anunciado e implementado por el sucesor de Batlle en la presidencia, Feliciano Viera- fue producto de su traspié en las urnas. La democracia política del sufragio universal y de la renovada coparticipación de los dos principales partidos, finalmente asegurada en la nueva Constitución, nació junto al imperativo político de la conciliación y del pacto, de la parsimonia para el cambio social, del recelo ante los impulsos reformistas hegemónicos. Entre las disposiciones innovadoras 
de esa nueva Constitución que entró en vigencia a partir de marzo de 1919 deben citarse: separación de la Iglesia del Estado, sufragio universal masculino, ampliación de las garantías electorales, establecimiento de un exótico poder ejecutivo bicéfalo (con un Presidente y un Consejo Nacional de Administración), reconocimiento de las empresas públicas, fijación de una secuencia electoral casi anual y flexibilización de los procedimientos de reforma constitucional, entre otras. De allí en adelante, a partir de esos marcos institucionales tan singulares, habrían de dirimirse los pleitos políticos fundamentales de una democracia de partidos, negociación y elecciones.

¿Qué era, en qué consistió esa tan mentada «política del alto" que predominó luego de la derrota electoral del batllismo en 1916? En términos generales, fue freno, detención, parálisis en los planes reformistas, pero no retroceso, al menos en un primer contexto. El freno al impulso reformista no se tradujo en la hegemonía de las derechas antibatllistas. En esa dirección, se impone señalar que también el viraje conservador tuvo su propio «alto». ${ }^{8}$

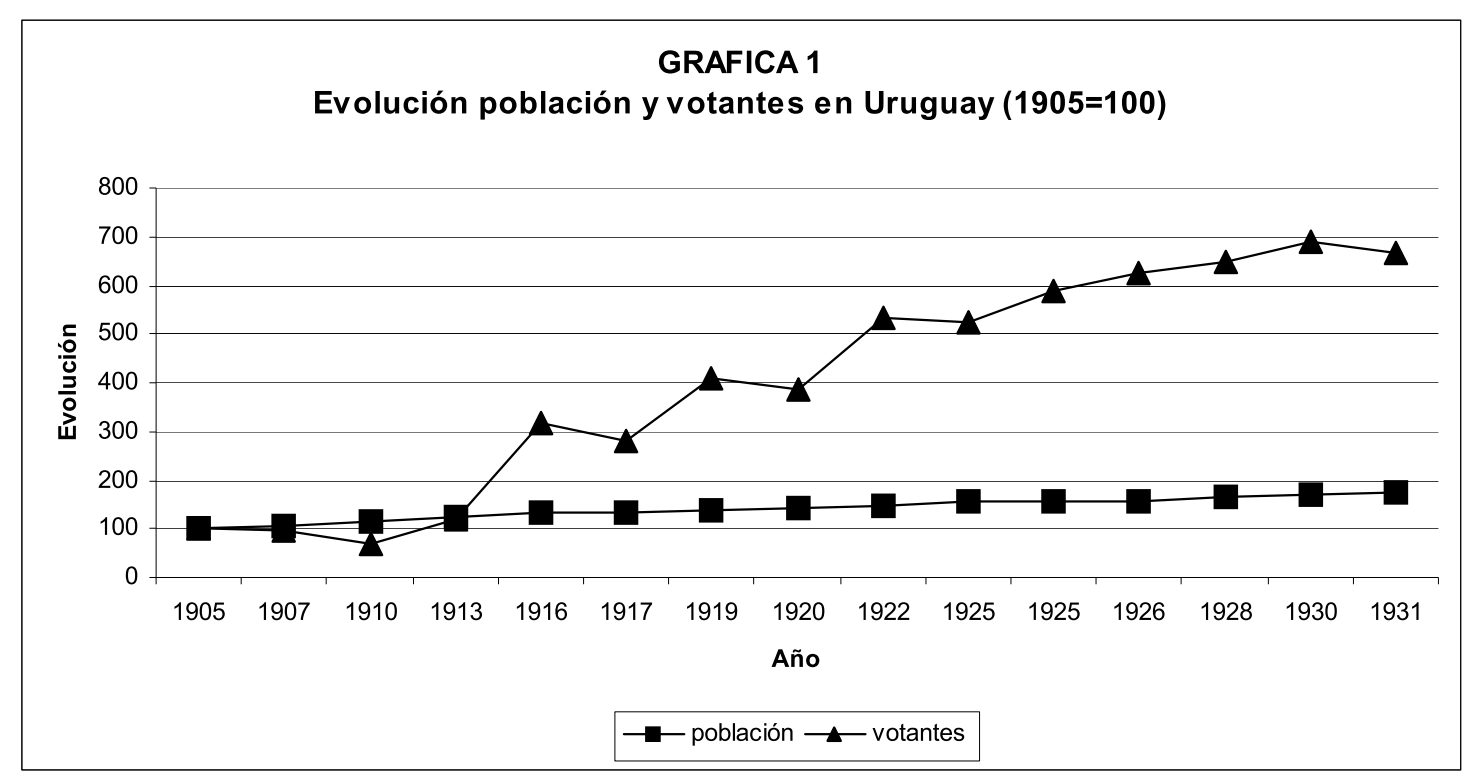

Asimismo, el sistema político uruguayo experimentó durante las primeras tres décadas del siglo XX una acelerada expansión electoral. Superados de manera progresiva los motivos que en el pasado habían quitado legitimidad ciudadana a las elecciones, el arbitraje electoral arrai-

\footnotetext{
${ }^{8}$ Caetano, (1992a).
} 
gó con mucha fuerza y celeridad en el seno de la sociedad uruguaya. Lo primero que debe destacarse al examinar las tendencias electorales de ese período tiene que ver con un aumento verdaderamente espectacular en el número de votantes. En la gráfica 1 puede observarse el vivo contraste entre la evolución de la población y del electorado efectivo, entre los habilitados para sufragar (ciudadanos varones mayores de 18 años) y aquellos que votaron de manera efectiva en las elecciones para la renovación de los principales Poderes Públicos entre 1905 y 1931. Lo primero que salta a la vista es el carácter explosivo del aumento de votantes, especialmente a partir de 1916 y después de la puesta en vigor de la Constitución de 1919, cuando se implantan las nuevas garantías para la emisión del voto.

En suma, el contexto uruguayo que recibía los impactos de la revolución rusa podía ambientar ciertas hipótesis iniciales: i) su influencia sería relativa, dada la primacía fuerte de la batalla ideológica entre «reformistas solidaristas» $\mathrm{y}$ «liberal conservadores», partícipes de un conflicto ideológico y político de fuentes diferentes; ${ }^{9}$ ii) por el contrario, su impacto se perfilaba como decisivo en el seno de unas izquierdas radicalizadas por la competencia reformista del batllismo y por la crisis económico-social vigente; iii) resultaba también previsible que los actores conservadores recrudecieran su prédica de «alarma social» con referencias directas o indirectas a la revolución rusa, en términos de un argumento de peso para confirmar el freno a las reformas; iv) sus consecuencias con seguridad no alterarían de manera significativa la opción del electorado, que fundamentaba sus opciones en este campo en otro tipo de asuntos y problemas. ${ }^{10}$

\section{El impacto decisivo en el movimiento sindical y en el seno de las izquierdas}

Como antes se ha señalado, en el campo de las izquierdas uruguayas de la época, el freno a las reformas batllistas de «avanzada» y los efectos de la crisis convergían con las informaciones que llegaban de la revolución rusa y de las movilizaciones del poderoso movimiento sindical argentino para generar expectación y una agitación movilizadora. Un

\footnotetext{
${ }^{9}$ Caetano, (2011).

${ }^{10}$ Nahum, (2007).
} 
informante policial integrado en el medio obrero decía en carta dirigida al jefe Político y de Policía de Montevideo,

Virgilio Sampognaro, el 8 de enero de 1918:

«La revolución rusa es el plato del día de todos los militantes ácratas, los que confían en que no tardará la Argentina en «oficiar la misa roja». (...) Los anarquistas de acá esperan caldear el ambiente para solidarizarse con la Internacional. (...) Si el calor que provocara la hoguera revolucionaria argentina fuera mayor, el fuego llegaría a pegarse aquí.» ${ }^{11}$

Pese al control relativo del giro político reformista del batllismo por las políticas más conservadoras y represivas de su sucesor colorado, Feliciano Viera, la agitación sindical tendió a concentrar la atención y los temores de las fuerzas empresariales y conservadoras. Por eso no pudo extrañar que las tendencias más revolucionarias e «internacionalistas», tanto en el campo anarquista como en el socialista, provinieran de sus militantes del campo sindical, radicalizados por la gravedad de la represión gubernamental frente a la renovada movilización de los trabajadores. Decía por entonces «La Huelga General», periódico de la resistencia obrera:

«Se quitaron la careta los intitulados amigos del obrero. En Montevideo impera el terror gubernativo. No se declaró oficialmente el Estado de Sitio pero de hecho existe. La policía apalea a mansalva. (...) El gobierno se vendió cínicamente a las empresas tranviarias» ${ }^{12}$

Se aludía de esta manera al primer gran conflicto sindical de 1918, impulsado por la Federación Obrera Marítima (FOM), el gremio más importante que controlaban los socialistas. Por su lado, los anarquistas no se quedaron atrás, impulsando a los gremios en los que tenían hegemonía para acompañar el movimiento huelguístico, por ejemplo los tranviarios y los frigoríficos. Pese a la mediación del propio Batlle y Ordóñez

\footnotetext{
${ }^{11}$ AGN. Archivo particular de Virgilio Sampognaro, caja 216, carpeta 22. carta de Francisco Corney a Virgilio Sampognaro del 08/01/1918. Cabe resaltar que Corney devino en informante policial luego de haber desempeñado importantes cargos dirigentes en el campo sindical, entre ellos el de Secretario General de la FORU.

${ }^{12}$ «La Huelga General. Órgano de los trabajadores en huelga». Boletín 2, Montevideo 14/08/ 1918.
} 
y de algunos de sus allegados más cercanos al campo de la izquierda, como Domingo Arena, la intransigencia del gobierno de Viera y de sus fuerzas represivas profundizaron la confrontación, la que en agosto derivó en cuatro días de huelga general, con muertos y heridos de ambos bandos. Tras el agravamiento de la conflictividad sindical estaba sin duda como telón de fondo el impacto de la «revolución rusa», que llegó incluso a provocar acercamientos impensables entre los dirigentes sindicales de la «izquierda socialista» y los anarquistas. En diciembre de 1918 Sampognaro llegó a denunciar un «complot maximalista» en el que aparecían confabulados socialistas y anarquistas, bajo el liderazgo de trabajadores rusos de origen judío, que en la visión del gobierno vierista eran «agentes de Lenine (sic)». ${ }^{13}$ Lejos de atenuarse, la conflictividad sindical se incrementó de manera virulenta en 1919. ${ }^{14}$ Ya no eran solo el impacto de la revolución rusa o la crisis económica social los factores que empujaban el proyecto de la «huelga general revolucionaria», sino que a ellos venían a sumarse el estallido de la «semana trágica» en Buenos Aires en enero de 1919. Decía a este respecto por entonces «La Defensa Comercial»:

«Pensar seriamente en la necesidad de oponerse al avance de las fuerzas proletarias es el deber primordial del momento. Quien sea elemento de orden y de trabajo no puede hallar exagerado esto que decimos. (...) Negar que el capital está en peligro (...) es (...) una acción suicida. Se impone la reacción.» ${ }^{15}$

La conflictividad sindical, iniciada ya a partir de la crisis de 1913 pero agravada de manera inusitada en 1918 y 1919, no cabe duda que tenía como telón de fondo -no único, como vimos, pero sí decisivo- el impacto político e ideológico del proceso de la revolución rusa. El propio devenir de esta daba lugar a fuertes debates en la prensa socialista, anarquista y obrerista. Acontecimientos como la Revolución de Febrero de 1917 en San Petersburgo, el retorno de Lenin y el lanzamiento sus «tesis de abril» exigiendo la revolución socialista, la Revolución de Octubre y la caída del gobierno provisional de Kerenski, el impacto de la Paz de Brest-

${ }^{13}$ López D’Alesandro, (1992): 32-33; Caetano, (1992): 83 y ss.

${ }^{14}$ La conflictividad sindical empujada por la revolución rusa no solo se circunscribió a Montevideo sino que también tuvo algunos focos de lucha en el interior del país. Muñoz, (2015).

15 «La Defensa Comercial», Montevideo, 06/04/1919, p. 1. «Las exigencias obreras». 
Litovsk en marzo de 1918, la fundación de la III Internacional en marzo de 1919, las resoluciones de sus primeros Congresos, ${ }^{16}$ las acciones represivas del gobierno bolchevique frente a las demandas anarquistas (como el aplastamiento del levantamiento de Kronstadt), entre otros acontecimientos, comenzaron a constituirse en los temas más debatidos en la prensa y en las asambleas de socialistas y anarquistas. Las tendencias que emergían tenían en muchos casos un largo proceso de fragua, pero el detonante de la revolución rusa las ponía en el centro de la escena y en más de un sentido las volvía inconciliables en sus posturas.

La dureza de la represión gubernamental frente a lo que daban en llamar el «complot soviético» (que llegó a la detención y deportación de muchos trabajadores como «leninistas sospechosos» de origen extranjero), la consolidación del freno a las reformas batllistas (que quitaba argumentos a los «socialistas moderados» que alentaban una «entente» con el reformismo) y la fortísima reacción de las fuerzas empresariales, confirmaban la creciente irreversibilidad de las diferencias. Asimismo, los propios itinerarios de la revolución soviética llevaban las controversias a un campo de definiciones tajantes.

Ya el estallido de la primera Guerra Mundial había marcada ciertas tensiones dentro del P. Socialista. Pese a que al inicio del conflicto bélico se dio la primacía neta de la tesis de la «neutralidad», la existencia de un «sector occidentalista» que marcaba matices frente al posicionamiento de los Estados Unidos, dio lugar más adelante a la división profunda entre «internacionalistas» $\mathrm{y}$ «reconstructores», no casualmente liderados por Eugenio Gómez ${ }^{17}$ y por Emilio Frugoni ${ }^{18}$ respectivamente. El estallido de la revolución rusa profundizó a un punto de no retorno las divisiones.

\footnotetext{
${ }^{16}$ En particular, la adopción de las «21 tesis de Lenin» aprobadas en el II Congreso del Kominterm celebrado en julio y agosto de 1920.

${ }^{17}$ Eugenio Gómez (1892-1973) fue no solo el promotor de la corriente «maximalista internacionalista» sino el verdadero líder fundacional del P. Comunista en 1920 y en 1921, a partir de la escisión del campo socialista. Expulsado del P. Comunista en 1955, fue autor de una obra de fuerte contenido revisionista bajo el título «Historia del Partido Comunista del Uruguay hasta el año 1951.»

${ }^{18}$ Emilio Frugoni fue el fundador del P. Socialista y su primer diputado electo en 1910. Luego de la escisión con los comunistas volvió a ser electo diputado en varias legislaturas. Fue también un destacado jurista y escritor, con una obra de perfil ideológico y político de envergadura. Fue designado Ministro Plenipotenciario del Uruguay ante la URSS entre 1944 y 1946. De esa experiencia surgió su libro de perfil crítico «La esfinge roja».
} 
En primer lugar, comenzaron a realizarse nuevamente actos «unitarios» entre socialistas y anarquistas en defensa de la revolución, algo que era interpretado por el viejo establishment de ambos campos como casi una herejía. Las diferentes posiciones comenzaron a cobrar plena visibilidad dentro del Partido Socialista. Mientras la postura de los «maximalistas» o «revolucionarios internacionalistas», liderada como vimos por Eugenio Gómez y con fuertes sustentos en el frente sindical partidario, se volvía cada vez más fuerte, otro sector más disperso hacía ver su posicionamiento «antibolchevique», con la crítica a la metodología que había depuesto a Kerenski y a su gobierno, a lo que venía a sumarse su repudio a la paz concretada luego con Alemania. Las autoridades partidarias, comandadas por Frugoni, se negaron a mediar en un diferendo ya inconciliable, pero desde los editoriales del vocero oficial «El Socialista» sostenían la «inviabilidad de la Revolución Bolchevique», al tiempo que rechazaban «la paz unilateral» firmada con Alemania, que a su juicio no podía significar otra cosa que «la victoria del imperialismo prusiano». ${ }^{19}$ El intento de Frugoni por situar a la dirigencia partidaria en una suerte de tercería mediadora no resultaba una estrategia muy convincente ni fundamentada, lo que el desenlace de la Guerra Mundial vino a poner de manifiesto de manera particular.

En medio de un generalizado movimiento de actos barriales a favor de la Revolución (en los que los militantes socialistas comparecían junto con los anarquistas «revolucionarios»), con un creciente apoyo en los sindicatos controlados por los socialistas y con un peso argumentativo que comenzó a ganar la prensa partidaria y hasta buena parte de las autoridades (bastiones persistentes del Frugoni fundador), poco a poco Eugenio Gómez y su fracción «maximalista» comenzaron a ganar la partida. Mientras en Europa parecía iniciarse la bancarrota de la Internacional socialdemócrata, en ancas del prestigio del triunfo soviético, los «comunistas» no perdieron el tiempo. Como se ha visto, en marzo de 1919 se reunió en Moscú el Primer Congreso de la Internacional Comunista, mientras poco más de un año después se realizaba el Segundo Congreso inaugurado el 19 de julio de 1920, que entre otras cosas estableció la indispensable adhesión a las «21 tesis de Lenin» (signadas por una adhesión total a la URSS y sus posturas, una «ruptura total y definitiva con el reformismo», entre otras posiciones maximalistas) como condición de ingreso a la Internacional Comunista. ${ }^{20}$

\footnotetext{
${ }^{19}$ López D’Alesandro, (1992): 137 y ss.
}

${ }^{20}$ López D’Alesandro, (1992): 196 y ss. 
Como ya era previsible, las resoluciones que por Congreso estableció el P. Socialista uruguayo tuvieron definiciones abrumadoras: la votación del ingreso a la Internacional Comunista se resolvió el 21 de setiembre de 1920 con 1297 votos de congresales a favor, 175 negativos y 275 abstenciones. ${ }^{21}$ Pese a su abrumadora derrota, Frugoni anunció su permanencia en el partido y fue elegido para integrar el nuevo Comité Ejecutivo del partido con 1197 adhesiones (el máximo de votos únicamente empatado por su archirrival Eugenio Gómez). Sin embargo, la definición en torno a las «21 tesis de Lenin» ya no dejaba espacio para ninguna conciliación. Nuevamente por abrumadora mayoría, en la noche del 17 al 18 de abril de 1921, los «maximalistas internacionalistas» (devenidos ahora en «comunistas» a secas) arrasaban a los «reconstructores» (ahora socialistas): 1007 votos frente a apenas $110 .{ }^{22}$ La ruptura tantas veces anunciada se consumaba en forma plena: de manera simbólica, el nuevo P. Comunista se quedaba con la «Casa del Pueblo», con el periódico «Justicia» y presentaba fechada la carta de renuncia como diputado de Emilio Frugoni, práctica tradicional por entonces. ${ }^{23}$

Algo similar ocurrió en el frente anarquista. La polarización se dio entre los «maximalistas» o «anarco dictadores» (que creían que no podían permanecer neutrales ni menos críticos frente a una revolución socialista triunfante) y los «anarcos puros», «anarco-puritas» o simplemente «puritas» (que denunciaban que nunca aceptarían una dictadura aunque fuera del proletariado). En este caso no hubo Congresos que definieran la correlación de fuerzas de uno y otro bando. ${ }^{24}$

El nuevo mapa de las izquierdas se proyectó como era de esperar en el plano del movimiento sindical. Al tiempo que varios sindicatos cambiaban de corriente hegemónica, la FORU se convirtió de inmediato en campo de batalla sindical e ideológica. Acusándose mutuamente de divisionistas, las dos fracciones del anarquismo uruguayo emergentes del impacto de la revolución rusa en Uruguay no aceptaron mantener una acción unificada en el frente sindical. La ruptura de la unidad del sindicalismo de hegemonía anarquista, representado desde 1905 por la FORU, luego de un largo y complejo proceso devino en la creación de la «Unión Sindical Uruguaya» (USU), cuya mayoría quedó en manos de

\footnotetext{
${ }^{21}$ López D’Alessandro, (1992): 215.

${ }^{22}$ López D’Alesandro, (1992): 233.

${ }^{23}$ Manini Ríos, (1972): 232-233.

${ }^{24}$ López D’Alesandro, (1992): 158 y ss.
} 
los «anarco-dictadores» en contra de los comunistas, socialistas y de los «puritas», sus contradictores del campo anarquista. En definitiva, tanto en el campo de las izquierdas políticas como dentro del movimiento sindical, el principal impacto de la revolución rusa venía a derivar en lo inmediato en un nuevo mapa de organizaciones, con mayor dispersión y enfrentamientos, así como con un debilitamiento innegable en su capacidad de influencia en el escenario nacional. ${ }^{25}$

\section{La recepción desde el campo del batllismo reformista}

La caracterización ideológica del «primer batllismo» de José Batlle y Ordóñez ha sido y es un tema de debate en la historiografía uruguaya. Catalogado como una «social democracia temprana», como una expresión de «liberalismo social» o «progresista», como «reformismo nacional», como una expresión particular de «republicanismo liberal», ${ }^{26}$ hasta como un ejemplo de «bonapartismo» ${ }^{27} \mathrm{o}$ «populismo», ${ }^{28}$ lo cierto es que en varias oportunidades, incluso en momentos del propio desarrollo de la revolución rusa, el batllismo fue acusado por el frente de fuerzas más conservadoras de su tiempo como «socialista» o como «avancismo jacobino». Incluso su líder fundacional, José Batlle y Ordóñez, fue presentado a menudo como el «Lenin uruguayo». Muchos de sus principales dirigentes de la época no vacilaron en autocalificarse como «socialistas sin bandera» y hasta hubo, como veremos más adelante, «batllistas» marxistas.

Por cierto que ni el batllismo como movimiento ni Batlle y Ordóñez fueron marxistas. Precisamente en 1917, año de la revolución rusa, se dio una larga polémica periodística entre el entonces Secretario General del P. Socialista (que luego se plegaría a la mayoría comunista de 1920 y 1921), Celestino Mibelli29 y el propio Batlle y Ordóñez. ${ }^{30}$ El debate fue promovido inicialmente por la polémica sobre suprimir o controlar al ejército, pero de inmediato devino en una controversia mucho

\footnotetext{
${ }^{25}$ López D’Alesandro. (1992): 262 y ss.

${ }^{26}$ Caetano, (2011).

${ }^{27}$ Louis, (1969).

28 Zubillaga, (1985).

${ }^{29}$ Celestino Mibelli fue a su vez expulsado del P. Comunista en 1926 acusado de «desviaciones oportunistas».

${ }^{30}$ Vanger, (1989).
} 
más amplia, abierta a otros temas como el de la postura de Batlle sobre el socialismo marxista. A tres meses escasos de la revolución bolchevique, Batlle señalaba entre otras cosas, luego de haber negado ser marxista o de aceptar el «odio de clases» como motor de la historia:

«Nuestra divergencia de opinión con el señor Mibelli estriba en que él piensa que la lucha política debe entablarse entre las clases (...) acomodada y el proletariado; y nosotros creemos que debe entablarse entre (...) reformistas y conservadores. El cree que la lucha debe ser de intereses; nosotros que debe ser de ideas. En esta lucha por la justicia, por la solidaridad, el señor Mibelli considera buen compañero al menesteroso por el simple hecho de serlo, aunque ese mismo, si pudiera, se convertiría en un explotador sin conciencia de sus semejantes y mirará como enemigo al rico por el solo hecho de serlo, aunque haya ricos que, aun contra su interés, estén dispuestos a pugnar por la supresión de toda injusticia en la distribución de la riqueza.» ${ }^{31}$

Al concluir su polémica con Mibelli, Batlle sostenía que un verdadero socialista debía apoyar al batllismo para hacer realizables muchas de sus propuestas. De hecho, el P. Socialista tenía un «programa mínimo» que postulaba para incentivar a los batllistas radicales a concretar «leyes de inspiración socialista pero de realización batllista». Sin embargo, como veremos, en los medios conservadores el impacto de la revolución rusa generaba «terror» y tenía mucho que ver con las posibilidades de resurgimiento del avancismo reformista del batllismo, a quien veía como un «aprendiz de brujo» que podía desatar fuerzas que luego no lograría controlar. Decía a este respecto Ramón Díaz desde las páginas del diario «La Mañana», vocero de la derecha colorada, nada menos que en abril de 1919:

« ¿Hasta dónde llegan las ideas comunistas del batllismo? ¿Es un partido socialista? 'Es un grupo de bolsheviquis (sic)? Nos parecería útil saberlo porque ello interesa grandemente a todos. iHasta podrían invocarse razones supremas de tranquilidad social! No vaya a ocurrir con eso de Lenine (sic), Trotsky y Cía, como ocurrió con el colegiado... Hay ya gentes que sueñan cosas horribles y que hasta dormidas tiemblan de miedo ante multitudes enfurecidas que piden el reparto general...». ${ }^{32}$

${ }^{31}$ Vanger, (1989): 191.

32 «La Mañana», Montevideo, 16/04/1919. «Del Dr. Ramón Díaz. ¿Y el programa?». 
Lo cierto es que las escisiones políticas que había sufrido el batllismo a lo largo de su trayectoria habían tenido como eje el mismo temor ideológico. En 1913, el entonces Ministro del Interior de Batlle durante su segunda presidencia, Pedro Manini Ríos, al frente de un amplio grupo de legisladores colorados que ya no respaldarían al gobierno, había argumentado «que no sabemos que quiere Batlle. (...) ... no lo acompañaremos en un avancismo «a outrance»: el Partido Colorado no es socialista ni va al socialismo». ${ }^{33}$ Algo similar diría el sucesor impuesto por el propio Batlle en la presidencia de la República, Feliciano Viera, nada menos que en 1919 y ya conquistada por acuerdo su presidencia en el Ejecutivo Colegiado del nuevo Consejo Nacional de Administración. Viera se separaría de Batle luego de rechazar su iniciativa de establecer una Asamblea Nacional de Gobierno, habilitada para interpelar y mandatar a las autoridades electas del partido, bajo el argumento de que esa nueva institución partidaria «iba en camino del Soviet»:

«... cuando lo vi a Batlle convertirse en el campeón de las ideas disolventes, ni yo ni mis amigos (...) creímos que estábamos en la obligación de tolerar y aceptar todas sus iniciativas. (...) Los colorados impersonales y los riveristas serán la nueva barra que en Cámara impedirá el triunfo de toda idea descabellada.» ${ }^{34}$

O sea que más allá de su expresa indicación de que ni él ni su partido eran de inspiración marxista, el impacto de la revolución rusa en Uruguay afirmaba la estrategia conservadora de acusar a Batlle y al batllismo de ser socialistas y de representar al frente del gobierno un desafío similar para los intereses empresariales que el de la naciente república soviética. En momentos en que como vimos, el freno a las principales reformas implementadas por el batllismo resultaba el principal objetivo interno de las derechas antibatllistas, la estrategia no parecía descabellada. El máximo ideólogo del conservadorismo uruguayo, una suerte de «Bossuet laico de nuestras clases altas» de acuerdo al juicio siempre punzante de Carlos Real de Azúa, ${ }^{35}$ José Irureta Goyena, se había encargado de establecerlo con meridiana claridad, en un discurso pronunciado en una asamblea rural celebrada en su honor en el departamento de

33 Caetano, (1992a): 130.

${ }^{34}$ Caetano, (1992b): 16.

${ }^{35}$ Real de Azúa, (1964): 85. 
Rocha en 1918, en el que había pronunciado el que tal vez fue el juicio más duro y adverso contra el primer batllismo en décadas:

«Los rurales necesitan que se les garantice cierto grado de estabilidad en las instituciones, $[\ldots]$ pero ustedes saben que entre tanto el inquietismo se agita y prevalece en las esferas del Capitolio. (...) Yo opino que el inquietismo es peor que el socialismo. Los socialistas persiguen una quimera pero al menos saben lo que quieren, y darían la voz de alto, si algún día aprisionaran la quimera. Los inquietistas reman siempre a favor del viento, y cuando no sopla el viento reman en contra del reposo. [...] El inquietismo no es moral, ni inmoral, es el movimiento por el movimiento, la efervescencia, la desazón, el mal de San Vito aplicado a la conducta del Estado». ${ }^{36}$

Sin embargo, más allá de su claridad de sus formulaciones doctrinarias, a Batlle le gustaba la discordia contra sus enemigos, provocarlos con la explicitación pública de aquellas de sus ideas más controvertidas, que no derivaban del cálculo político sino de la voluntad del gladiador. Cuando murió Lenin en enero de 1924, Batlle no se sintió para nada inhibido de que en su diario apareciera un obituario que sin duda escandalizó a sus adversarios más conservadores. Su título ya lo decía todo: «De pie. Murió Lenin.»

«El fallecimiento del jefe del comunismo ruso es un acontecimiento que pone de inmediato en segundo término a todos los demás que ocurren en el mundo. Podrá tenerse ideas muy adversas a las que sustentaba este apóstol de mejores aunque irrealizables devenires, pero no se podrá negar que con él se extingue un magnífico ejemplar humano, uno de esos personajes apasionantes que dan significación a toda una época y sirven para fijarla en la historia. (...) Lenin fue el verbo de la revolución. Con él se apagan la doctrina y el nervio que la sostenían. (...) Lenin era en estos momentos la palabra de sensatez y de cordura, la mirada avizora y penetrante, la mano que no temblaba en el timón. No juzgamos sus ideas con las que no podemos estar de acuerdo, sino sus condiciones de orientador de muchedumbres (...). De cualquier modo, desaparece con Lenin un hombre excepcional, ante cuya tumba, prematuramente abierta, sería pueril no descubrirse con respeto.» ${ }^{37}$

\footnotetext{
${ }^{36}$ Irureta Goyena, (1948): 270 y ss.

37 «El Día», Montevideo, 24/01/1924. Cita extraída de Cuadernos de Marcha. No $^{\circ} 2$, diciembre de 1969, pp. 79 y 80. Batlle. Tomo II.
} 
Debe decirse que con igual apertura y tal vez justificando al menos en parte la neurosis de sus enemigos conservadores que asociaban al batllismo con el impacto local de la Revolución Rusa, en vida Batlle supo acoger en las filas de su partido a un dirigente joven, Julio César Grauert y a su Agrupación «Avanzar», que sí se definían como socialistas y hasta como marxistas en muchos casos. ${ }^{38}$

\section{Algunos ecos de la reacción conservadora}

La réplica de los voceros más connotados de las derechas políticas y de los círculos empresariales, como vimos, tampoco vacilaron en vincular el impacto local de la revolución rusa con la agitación sindical y las posibilidades de un resurgimiento de las reformas en las políticas públicas, de la mano de un fortalecimiento político del batllismo y de aquellos a quienes consideraba sus «socios encubiertos». A partir de una iniciativa originalmente surgida en la Cámara Mercantil de Productos del País en agosto de 1918, se dispuso convocar a los demás gremios empresariales para conformar una liga patronal, se decretó un «boycot patronal» en adhesión a las medidas represivas del gobierno, se conminó con plazos perentorios a los huelguistas al retorno al trabajo bajo la amenaza del despido inmediato y a la inclusión de los resistentes en una «lista negra» para que ninguna empresa establecida en el país les diera trabajo. ${ }^{39}$ En octubre de 1918 quedó pronto el proyecto para crear la «Alta Comisión del Comercio y de la Industria», con el cometido de enfrentar las huelgas obreras así como todas aquellas leyes o acciones gubernativas que de acuerdo a su criterio afectaran sus intereses. ${ }^{40}$

Como vimos, la agitación sindical y el «terror» conservador recrudecieron en 1919, de la mano de las noticias alarmantes que llegaban de Europa pero también de los ecos atemorizantes que provenían de Buenos Aires y del tenor de la ola huelguística en la vecina orilla. «La Defensa Comercial» insistía en sus editoriales sobre el «momento de lucha que atraviesa el capital en el Río de la Plata», redoblando sus llamados a la acción en un «momento que no es de indecisiones y temor.» ${ }^{41}$ La renova-

\footnotetext{
${ }^{38}$ Cfr. Didizián, (1967).

${ }^{39}$ Caetano, (1992): 89 y ss.

40 Caetano, (1992): 90-95.

${ }^{41}$ «La Defensa Comercial». Montevideo, 13/05/1919, p. 1. «En plena defensa».
} 
ción de conflictos especialmente iniciados por los sindicatos portuarios, tranviarios y de la construcción, reforzaron las medidas represivas impulsadas por la «Alta Comisión de la Industria y del Comercio», llegando algunas empresas a ofrecer al gobierno «personal especializado» para apoyar la represión policial sobre los huelguistas. Mientras tanto, los informes alarmistas también le llegaban al Jefe de Policía de Montevideo por parte de sus informantes radicados en Buenos Aires:

«Puedo asegurar a Usted que la propaganda maximalista es un asunto de lo más serio y confío que las autoridades de ahí tomarán severísimas medidas para quebrantarla al nacer. (...) No hay duda que ellos harán todo empeño para provocar un movimiento de carácter maximalista $\mathrm{el}^{\circ}$ de mayo. iOjo a cualquier movimiento sospechoso pues los agentes van y vienen de ésta a aquella!» ${ }^{42}$

Los efectos de la represión gubernamental y de las acciones anti obreras de las gremiales empresariales golpearon duramente al movimiento sindical. La fuerza de los sindicatos ya se mostró mucho menor en los años siguientes, bajando de manera considerable incluso las estimaciones de la época sobre la tasa de afiliación sindical. ${ }^{43} \mathrm{El}$ giro conservador del «Alto» en las reformas dispuesto desde 1916 por el entonces Presidente Viera se consolidó. Pero el «terror» conservador frente al impacto de la revolución rusa y su articulación con los fenómenos locales que se consideraban peligrosos no amainó. La persistencia de su preocupación los llevó hasta intentar la creación de un partido empresarial bajo el nombre opaco de «Unión Democrática» en 1919, experiencia que terminó en un ominoso fracaso. ${ }^{44}$ A este respecto, «La Defensa Comercial» insistía en agosto de 1920:

«Las controversias políticas son en este país el plato preferido, el entretenimiento único (...). La mayoría vive de la política y para la política. (...) Es la política del error, la (...) roja cinta cinematográfica que desarrollándose en las estepas del Cáucaso atraviesa el mundo para enternecer a ciertos políticos que solamente guardan posiciones por las promesas lisonjeras que los crédulos creen. (...) Olvi-

\footnotetext{
42 AGN. Archivo particular de Virgilio Sampognaro, caja 219, carpeta 3, foja 17. Carta anónima dirigida a Virgilio Sampognaro fechada en Buenos Aires el 22/04/1919.

${ }^{43}$ Rodríguez, (1966).

${ }^{44}$ Caetano, (1992): 119 y ss.
} 
demos un poco la política, principalmente esa política malsana que traen los vientos de la vieja Europa. (...) Dejemos a esos pequeños «Lenines» y dediquémonos (...) a intensificar el trabajo...» 45

Por su parte, desde el sector agropecuario, hegemónico dentro de las fuerzas del gran capital, Irureta Goyena sacaba lecciones de la coyuntura vivida y levantaba en sus discursos la consigna de «aburguesar al peón» y al trabajador. Ya pasadas las contiendas y los «temores» más acuciantes, en su discurso ante el V Congreso de la Federación Rural en 1921, el líder e ideólogo conservador señalaba:

«... hay moldes que se han roto de una vez y (...) para siempre jamás, y el comunismo es uno de ellos. (...) Admitamos (...) que los hombres en sociedad se dividen en dos categorías: los que tienen más comida que apetito y los que tienen más apetito que comida. (...) ¿Quién es capaz, al fin y al cabo, de ponerle remedio a este desequilibrio? (...) El único medio eficaz para ello es el ahorro, que suple el hambre y la escasez de mañana con la saciedad o la abundancia de hoy; el primer capitalista fue el primer cazador que volvió al bosque antes de consumir todas las presas de su última cacería; la abeja es capitalista, la cigarra es comunista, el zángano es leninista.» ${ }^{46}$

Pasado en parte lo más amenazante de la coyuntura que había apurado la reacción conservadora de años anteriores, de lo que se trataba era de aprender de lo vivido, consolidar las organizaciones de «defensa del capital», afirmar los principios y controlar sobre todo al principal enemigo, que en la visión de los empresarios y del gran capital del Uruguay de la época era la posibilidad de un retorno del «avancismo» del batllismo reformista, ese «aprendiz de brujo» «inquietista» del que no dejaban de recelar. El principal impacto de la revolución rusa en el Uruguay de todos modos no fue menor: cambió los mapas de la izquierda política y social, transformó los contornos del movimiento sindical, contribuyó a nuevas divisiones ideológicas dentro del P. Colorado y del batllismo, galvanizó ciertas convicciones y prácticas en el accionar del frente

\footnotetext{
45 «La Defensa Comercial». Montevideo, 17/08/1920, p. 1. «El trabajo y la política.»

${ }^{46}$ Irureta Goyena, 1948: 294 y 295.
} 
conservador. Pero en lo fundamental, no pudo alterar nada sustantivo en aquella democracia de partidos y de negociación. Un segundo impulso reformista volvería hacia fines de los veinte, pero como consecuencia de otros procesos locales e internacionales. ${ }^{47}$

\section{Bibliografía}

BARRÁN, José Pedro-NAHUM, Benjamín, Batlle, los estancieros y el Imperio Británico. Tomo I. El Uruguay del Novecientos. Montevideo: Ediciones de la Banda Oriental.

BARRÁN, José Pedro-NAHUM, Benjamín, Batlle, los estancieros y el Imperio Británico. Tomo VI. Crisis y radicalización. (1913-1916). Montevideo: Ediciones de la Banda Oriental.

CAETANO, Gerardo (1992a), La República Conservadora. Tomo I. El «alto» a las reformas. (1916-1929). Montevideo: Fin de Siglo.

CAETANO, Gerardo (1992b), La República Conservadora. Tomo II. La «guerra de posiciones». (1916-1929). Montevideo: Fin de Siglo.

CAETANO, Gerardo-JACOB, Raúl, (1989), El nacimiento del terrismo (1930-1933), Tomo I, Montevideo: Ediciones de la Banda Oriental.

CAETANO, Gerardo-JACOB, Raúl, (1990), El nacimiento del terrismo (1930-1933), Tomo II, Camino al Golpe. Montevideo: Ediciones de la Banda Oriental.

CAETANO, Gerardo-JACOB, Raúl, (1991), El nacimiento del terrismo (1930-1933), Tomo III, El golpe de Estado. Montevideo: Ediciones de la Banda Oriental.

CAETANO, Gerardo-RILLA, José, (1991) «La izquierda uruguaya y el 'socialismo real'. Visión histórica de algunas trayectorias», en Varios, La herencia del «socialismo real», Montevideo, FESUR, 9-59.

CAETANO, Gerardo, (2011), La República Batllista. Montevideo: Ediciones de la Banda Oriental.

«Cuadernos de Marcha», (1969), No 32, Batlle II. Montevideo, Editorial Marcha.

${ }^{47}$ Cfr. Caetano-Jacob, (1989) y (1990). 
DIDIZIÁN, Kurken, (1967), Julio César Grauert discípulo de Batlle. Recopilación de los editoriales de «Avanzar». Montevideo: Avanzar.

FRUGONI, Emilio, (1947), Génesis, esencias y fundamentos del Socialismo. Tomos I y II. Buenos Aires: Americalee.

FRUGONI, Emilio, (1990), La esfinge roja. Tomos I y II. Montevideo, Cámara de Representantes.

GÓMEZ, Eugenio, (1990) Historia del Partido Comunista del Uruguay hasta el año 1951 que fuera publicado por Gómez en 1961. Montevideo: Eco.

GRAUERT, Julio César-CERUTI CROSA, Pedro, (1927) Los dogmas, la enseñanza y el Estado. Montevideo: Avanzar.

IRURETA GOYENA, José, (1948), Discursos del Dr. José Irureta Goyena. Homenaje a su memoria. Montevideo: Tipografía Atlántida.

LÓPEZ D’ALESANDRO, Fernando, (1992), Historia de la izquierda uruguaya. Tomo II. La izquierda durante el batllismo (1911-1918). Primera y Segunda Parte. Montevideo: Ediciones del Nuevo Mundo.

LÓPEZ D’ALESANDRO, Fernando, (1992), Historia de la izquierda uruguaya. La fundación del Partido Comunista y la división del Anarquismo. Montevideo: Vintén Editor.

LOUIS, Julio A., (1969), Batlle y Ordóñez. Apogeo y muerte de la democracia burguesa. Montevideo: Natura Libros.

LUISI, Luisa, (1936), Agrupación batllista «Avanzar. Discurso pronunciado por Luisa Luisi en la Convención del Partido Batllista en el tercer aniversario de la muerte de Julio César Grauert. Montevideo:Avanzar.

MANINI RÍOS, Carlos, (1972), Una nave en la tormenta. Montevideo: Imprenta Letras S. A.

MUÑOZ, Pascual, (2015), Cultura Obrera en el interior de Uruguay. Salto, Paysandú y Rocha (1918-1925). Montevideo: Lupita ediciones.

NAHUM, Benjamín, (2007), Estadísticas históricas del Uruguay (19001950). Montevideo: Universidad de la República.

REAL DE AZÚA, Carlos, (1964), Antología del Ensayo Uruguayo 
Contemporáneo. Tomo I. Montevideo: Universidad de la República.

RODRÍGUEZ, Héctor, (1966[1965]), Nuestros Sindicatos (18651965). $2^{\mathrm{a}}$ edición. Montevideo: Centro de Estudiantes de Derecho.

VANGER, Milton, (1989), ¿'Reforma o Revolución? La polémica Batlle-Mibelli. 1917. Montevideo: Ediciones de la Banda Oriental.

ZUBILLAGA, Carlos, (1985), «El batllismo, una expresión populista», en Jorge BALBIS et alli, El primer batllismo. Cinco enfoques polémicos. Montevideo: Ediciones de la Banda Oriental.

\section{Prensa consultada}

La Defensa Comercial, 1918-1923.

La Huelga General. Órgano de los trabajadores en lucha. 1918.

La Mañana, 1918-1923.

El Día, 1918-1923.

Justicia, 1918-1923.

El Socialista, 1917-1919.

\section{Archivo consultado}

Archivo General de la Nación. Archivo Particular de Virgilio Sampognaro. 